\title{
Effects of Progressive Muscle Relaxation and Transcendental Meditation Treatment on Rifle Shooting Performance
}

\author{
Dr. Baljit Singh Sekhon \\ Dy. Director Sport, Nagaland University, Nagaland
}

\begin{abstract}
It has become necessary to place a greater emphasis on psychological and mental training methods in competitive shooting sports to achieve top performance. The widely held thought that tends to associate shooting with aggressive manners is totally mistaken. On the contrary, the shooting sport demands calmness, concentration combined with physical fitness. Shooting is a learned skill that is developed through physical and psychological practices. In this study a total of 39 male, national level rifle shooters were selected. They were divided into three groups $i$. e. transcendental meditation, progressive relaxation/imagery and control group. The result of the study indicated that the progressive relaxation group showed significant improvement pre to post experiment on the rifle scores and transcendental meditation group showed non-significant improvement on the rifle scores. The purpose of this study was to investigate the effects of transcendental meditation and progressive muscle relaxation treatment on rifle shooting performance.
\end{abstract}

Keywords: Progressive Muscle Relaxation, Anxiety, Transcendental Meditation, Shooting Performance.

\section{Introduction}

Successful training in competitive sports or any performance-oriented sport is based on the scientific work up of specific physical and psychological as well as technical and didactic elements required for performance. Shooting requires a high level of mental discipline. All branches of the shooting sports have one element in common-success in any one is heavily reliant on mental skills (Kratzer 1982). The shooting sport is mostly referred as a "sport of the mind". One would therefore expect that mental make-up would play a very large role in determining the success or failure of a shooter. Sekhon (2009) reveals that systematic measurements of personality characteristics show this to be the case.

In order to do well at shooting you need to be relaxed, confident and focused and in addition, you also need to have a methodical routine before you pull the trigger. E. G. Hall (1983) conducted a controlled experiment to compare the effect of transcendental meditation versus progressive muscle relaxation versus no treatment. Anxiety in varying levels is an integral part of competitive shooting sports and various relaxation methods are developed to make anxiety less severe.

A method used to overcome anxiety - with a special emphasis on the promotion of relaxation - was introduced in psychotherapy by Edmund Jacobson (1938) in the early 1920s. This was termed "progressive relaxation" and also known as "systematic muscular relaxation" and was later applied in sport medicine. Progressive muscle relaxation (or PMR) is a technique for reducing anxiety by alternately tensing and relaxing the muscles. Progressive relaxation involves alternately tensing and relaxing the muscles. Transcendental meditation is a relaxation technique frequently proposed as a possible method to alleviate the specific anxiety associated to competitive sports. Transcendental meditation has been associated with an increase in alpha activity in the brain (indication of increased relaxation), decrease in metabolic rate, heart rate, bold pressure, galvanic skin response and an increase in blood flow to the skeleton muscles.

\section{Subject and Methods}

The subjects in this investigation were 39 male air rifle shooters, aged from 18 to 25 years from the various states who had participated in all India inter-university, pre national and national shooting championship. The subjects were randomly assigned to one of three experiment groups (13 male in each group: transcendental meditation, progressive muscle relaxation and control group. All subjects received same shooting instructions routinely given for the six week treatment phase. During the first week of the treatment period, each subject fired as presented in Table $-\mathrm{I}$

Table 1: Course of Fire

\begin{tabular}{|c|c|c|}
\hline $\begin{array}{c}\text { S } \\
\text { No. }\end{array}$ & Particular & Remarks \\
\hline 1 & Preparation time & 10 mnts \\
\hline 2 & Sighting time & 5 mnts \\
\hline 3 & Sighting shots & Unlimited \\
\hline 4 & $\begin{array}{c}\text { Competition/final } \\
\text { shots }\end{array}$ & 10 Shot/fire \\
\hline 5 & Shot per target & Single shot \\
\hline 6 & No. of shots & 10 shots \\
\hline 7 & Max scores per shot & 10 scores \\
\hline 8 & Target & $\begin{array}{c}\text { ISSF Air rifle } \\
\text { Targets }\end{array}$ \\
\hline 9 & Total score of test & $\begin{array}{c}10 \text { X } 10=100 \\
\text { Scores }\end{array}$ \\
\hline 10 & Timing & $\begin{array}{c}\text { As per rifle Final } \\
\text { Match }\end{array}$ \\
\hline
\end{tabular}

The two scores were averaged for a baseline measure of shooting ability. Rather than using self-report indications of anxiety reduction or relaxation, actual performance scores with the rifle were compared to determine effectiveness of the treatment. The subject in the transcendental meditation 


\section{International Journal of Science and Research (IJSR) \\ ISSN (Online): 2319-7064 \\ Index Copernicus Value (2013): 6.14 | Impact Factor (2015): 6.391}

group received instructions from a certified and trained instructor. This group met a total of 13 hours with instructor, going over seven prearranged steps. After this training the subjects practiced transcendental meditation twice a day for 25 minutes through the remainder of the six week treatment period. Subjects in the progressive muscle relaxation group received 13 hour instructions from an experienced/trained instructor. Subject were taught to differentiate between a state of tension and a state of relaxation and then learned how to use visual imagery in mentally practicing course of fire with the rifle. Subjects were also instructed to practice their techniques twice a day for 25 minutes and were monitored to ensure that practice was done. At the end of the six-week treatment period, subjects in all groups again fired a course of fire as mentioned in Table- I. The two scores were averaged to arrive at post-treatment score. In analysis of the results, scores for the individual fire along with the total courses were compared pre-to post-treatment to see if any of groups showed significant differences over the others. All shooters, at some time in their matches, experience anxiety.

\section{Results}

The pre-treatment and post-treatment data was statistically examined for significance, if any, applying analysis of covariance. After the statistical analysis of the data, the mean scores pre-to post-treatment for all three groups prepared and the same is shown in table:

Table 2: Descriptive Statistics

Dependent Variable: Shooting

\begin{tabular}{|c|c|c|c|c|}
\hline Group & Treatment & Mean & Std. Deviation & $\mathrm{N}$ \\
\hline Transcendental Meditation & Pre & 90.6154 & 1.38675 & 13 \\
\cline { 2 - 5 } & Post & 93.6923 & 1.49358 & 13 \\
\cline { 2 - 5 } & Total & 92.1538 & 2.11078 & 26 \\
\hline Progressive Muscle Relaxation & Pre & 90.4615 & 1.45002 & 13 \\
\cline { 2 - 5 } & Post & 94.3077 & 1.37747 & 13 \\
\cline { 2 - 5 } & Total & 92.3846 & 2.40128 & 26 \\
\hline \multirow{3}{*}{ Control } & Pre & 91.0769 & 1.75412 & 13 \\
\cline { 2 - 5 } & Post & 91.3077 & 1.70219 & 13 \\
\cline { 2 - 5 } & Total & 91.1923 & 1.69751 & 26 \\
\hline \multirow{2}{*}{ Total } & Pre & 90.7179 & 1.52088 & 39 \\
\cline { 2 - 5 } & Post & 93.1026 & 1.98408 & 39 \\
\hline & & 91.9103 & 2.12704 & 78 \\
\hline
\end{tabular}

Table 3: Tests of Between-Subjects Effects

\begin{tabular}{|c|c|c|c|c|c|}
\hline Source & Type III Sum of Squares & Df & Mean Square & F & Sig. \\
\hline Corrected Model & $178.833^{\mathrm{a}}$ & 5 & 35.767 & 15.189 & .000 \\
\hline Intercept & 658904.628 & 1 & 658904.628 & $2.798 \mathrm{E} 5$ & .000 \\
\hline Group & 20.795 & 2 & 10.397 & 4.416 & .016 \\
\hline Treatment & 110.885 & 1 & 110.885 & 47.091 & .000 \\
\hline Group * treatment & 47.154 & 2 & 23.577 & 10.013 & .000 \\
\hline Error & 169.538 & 72 & 2.355 & & \\
\hline Total & 659253.000 & 78 & & & \\
\hline Corrected Total & 348.372 & 77 & & & \\
\hline
\end{tabular}

a. R Squared $=.513$ (Adjusted R Squared $=.480$ )

Table 4: Multiple Comparisons

Dependent Variable: Shooting

\begin{tabular}{|c|c|c|c|c|c|c|c|}
\hline & \multirow[b]{2}{*}{ (I) group } & \multirow[b]{2}{*}{ (J) group } & \multirow[b]{2}{*}{ Mean Difference (I-J) } & \multirow[b]{2}{*}{ Std. Error } & \multirow[b]{2}{*}{ Sig. } & \multicolumn{2}{|c|}{ 95\% Confidence Interval } \\
\hline & & & & & & Lower Bound & Upper Bound \\
\hline LSD & control & Progressive & $-1.1923^{*}$ & .42559 & .007 & -2.0407 & -.3439 \\
\hline & & Trancen & $-.9615^{*}$ & .42559 & .027 & -1.8099 & -.1131 \\
\hline & Progressive & control & $1.1923^{*}$ & .42559 & .007 & .3439 & 2.0407 \\
\hline & & Trancen & 2308 & .42559 & .589 & -.6176 & 1.0792 \\
\hline & Trancen & control & $.9615^{*}$ & .42559 & .027 & .1131 & 1.8099 \\
\hline & & Progressive & -.2308 & .42559 & .589 & -1.0792 & .6176 \\
\hline
\end{tabular}

Based on observed means.

The error term is Mean Square (Error) $=2.355$.

*. The mean difference is significant at the .05 level.

\section{Conclusion}

The unique quality of competitive sports, including shooting, is that their successful completion requires overcoming difficulties which place great strain on all of the athlete's energies, physical and psychological. In present study the progressive relaxation group showed statistically significant improvement pre to post treatment on the total scores of course of fire in rifle shooting. The other changes 
recorded were statistically insignificant. The transcendental meditation group showed a little improvement on result, but this was not significant difference and could have been accredited to probability alone. These results do not essentially point out that transcendental meditation has no advantageous application to shooting sports.

\section{References}

[1] B. Hinchliffe, K. Target rifle Shooting, David \& Charles London, (1981).

[2] Barlow \& Craske (2006), Worry, Oxford University Press, Inc., p. 53, ISBN 0-19-530001-7

[3] Bob Hickey , (1996) Successful Rifle Shooting, STP Books, Tucson.

[4] Dreilich Beath \& Barth Kartrin (2010), Training Shooting Sports, Munich, Meyer \& Meyer Verlag.

[5] Hall, E. G., (1983) Ready, aim, fire...... The efficacy of transcendental meditation and progressive relaxation with imagery for enhancing rifle marksmanship, Unpublished Manuscript. Department of Physical Education, Louisiana State University, Baton Rouge, LA 70803.

[6] Hanenkrat, F.T., and Pullum, William, (1997) Position Rifle Shooting, Target Sports Education Centre, Ohio.

[7] Herbert Benson; Klipper, Miriam Z. (2001). The Relaxation Response. New York, NY: Quill. p. 61. ISBN 978-0-380-81595-1..

[8] Jacobson, E. (1938). Progressive Relaxation. Chicago: University of Chicago Press

[9] Kratzer. H. (1982) Pulling the Trigger: Some Remarks on its Psychological Regulation, Munich, UIT Journal, 3, 17, 31, 33.

[10] Reynolds, Mike (1986) Shooting Made Easy, Oxford, The Crowood Press.

[11] Sekhon, Baljit Singh (2012), Rifle Target Shooting, Delhi, Sports Publications.

[12] Stephen T.; Sinatra, Roberts, James C.; Zucker, Martin (2007). Reverse Heart Disease Now: Stop Deadly Cardiovascular Plaque Before It's Too Late. Wiley. p. 192. ISBN 978-0-470-22878-4.

[13] Wolpe, J. \& Lazarus, A.A. (1966) Behavior therapy technique. New York. Pergamon Press.

[14] Yur'yev, A.A., (1985) Competitive Shooting, National Rifle Association of America, Washington. 